\title{
Effect of the PI3K/AKT signaling pathway on hypoxia-induced proliferation and differentiation of bone marrow-derived mesenchymal stem cells
}

\author{
LINGLING SHENG* , XIYUAN MAO*, QINGXIONG YU and DONG YU \\ Department of Plastic and Reconstructive Surgery, Shanghai Ninth People's Hospital, \\ School of Medicine, Shanghai Jiao Tong University, Shanghai 200011, P.R. China
}

Received June 18, 2015; Accepted September 9, 2016

DOI: $10.3892 /$ etm.2016.3917

\begin{abstract}
Bone marrow-derived mesenchymal stem cell (BM-MSC) transplantation has been demonstrated to be an effective way of augmenting angiogenesis of ischemic tissue. The low oxygen conditions in ischemic tissue directly affect the biological behavior of engrafted cells. However, to date, the mechanism through which hypoxia regulates self-renewal, differentiation and paracrine function of BM-MSCs remains unclear. Clarification of this mechanism would be beneficial to the use of stem cell-based therapy. The PI3K/AKT pathway has been extensively investigated for its role in cell proliferation, cell transformation, paracrine function and angiogenesis. The present study aimed to analyze the role of PI3K/AKT pathway in hypoxia-induced proliferation of BM-MSCs and their differentiation into endothelial cells in vitro by the application of LY294002, a PI3K/AKT pathway inhibitor, with cells cultured in normoxia serving as a control. The results showed that rat BM-MSCs at passage 3 and 4 displayed only few phenotypical differences in the expression of surface antigens as detected by flow cytometry. When compared with the cells treated in normoxia, the proliferation of BM-MSCs in hypoxia was promoted, a greater number of cells expressed CD31 and a higher expression of vascular endothelial growth factor was observed after culture in hypoxic conditions. However, by inhibiting with LY294002, these changes induced by hypoxia were partly inhibited. In conclusion, the present study showed that the PI3K/AKT pathway served an
\end{abstract}

Correspondence to: Dr Dong Yu, Department of Plastic and Reconstructive Surgery, Shanghai Ninth People's Hospital, School of Medicine, Shanghai Jiao Tong University, 639 Zhizaoju Road, Shanghai 200011, P.R. China

E-mail: drdongyu@gmail.com

*Contributed equally

Key words: bone marrow-derived mesenchymal stem cells, hypoxia, phosphatidylinositol 3-kinase/protein kinase B pathway, differentiation important role in hypoxia-enhanced in vitro proliferation of BM-MSCs and their differentiation into endothelial cells and paracrine vascular endothelial growth factor.

\section{Introduction}

In recent years, studies based on animal and clinical trials have demonstrated the potential value of bone marrow-derived mesenchymal stem cell (BM-MSC) transplantation in augmenting angiogenesis of ischemic tissue, such as in myocardial infarction, stroke and skin flaps (1-5). In ischemic tissue, oxygen concentration markedly decreases, and influences the biological behavior of engrafted cells directly (6-8).

BM-MSCs are multipotent cells that can be induced to terminally differentiate into multiple lineages and secrete various cytokines, such as vascular endothelial growth factor (VEGF), epidermal growth factor and insulin-like growth factor $(9,10)$. In vivo, BM-MSCs are located near bone surfaces and perivascular niches, both of which have low levels of oxygen supply $(11,12)$. Therefore, oxygen tension is currently recognized as a crucial component of the stem-cell 'niche' that maintains the proliferative capacity and functions of BM-MSCs. The effect of hypoxic culture conditions may decrease the cell expansion time and induce the differentiation of BM-MSCs when compared with the standard protocols $(13,14)$. In addition, BM-MSCs paracrine more angiogenesis-associated cytokines subsequent to culturing under hypoxic conditions, including basic fibroblast growth factor (bFGF), VEGF, interleukin-6 (IL-6) and IL-8 (15). To date, the mechanism through which hypoxia regulates self-renewal, differentiation and paracrine of BM-MSCs remains unclear.

The phosphatidylinositol 3-kinases (PI3Ks) and their downstream target AKT are a conserved family of signal transduction enzymes that has been investigated extensively for its roles in cell proliferation, cell transformation, paracrine function and angiogenesis (16-18). Therefore, in the present study, the activation of PI3K/AKT pathway in BM-MSCs cultured under hypoxic conditions was detected. In addition, the PI3K/AKT pathway-mediated cellular responses were examined, including proliferation, differentiation into endothelial cells and paracrine function. 


\section{Materials and methods}

Cell culture. All the animal procedures were approved under the guidelines of Shanghai Jiao Tong University Medical Center and the Institutional Animal Care and Use Committee (Shanghai, China). Ten male Wistar rats (3-week-old; weight, $25-30 \mathrm{~g}$ ) were sacrificed with $3 \%$ sodium pentobarbital (Xinya, Inc., Shanghai, China). Next, bone marrow (BM) cells were flushed with $2 \mathrm{ml}$ Dulbecco's modified Eagle's medium (DMEM; Gibco-BRL; Thermo Fisher Scientific, Inc., Grand Island, NY, USA) from the femur and tibia of the rats. To remove the red blood cells from the BM cells, red blood cell lysis buffer (Sigma-Aldrich, St. Louis, MO, USA) was added for $10 \mathrm{~min}$, and centrifuged at $800 \mathrm{x} \mathrm{g}$ for $5 \mathrm{~min}$ at room temperature. Then, $1 \times 10{ }^{6}$ remaining BM cells were plated in a $100 \mathrm{~mm}$ dish with $10 \mathrm{ml}$ DMEM supplemented with $10 \%$ fetal bovine serum (Gibco-BRL; Thermo Fisher Scientific, Inc.) and $1 \%$ penicillin/streptomycin (Sigma-Aldrich) and cultivated in a humidified atmosphere with $20 \% \mathrm{O}_{2}$ and $5 \% \mathrm{CO}_{2}$ at $37^{\circ} \mathrm{C}$ (Thermo Scientific BBD $6220 \mathrm{CO}_{2}$ incubator; Omnilab, Bremen, Germany). After 3 days of culture, the medium and non-adherent cells were replaced, while adherent BM-MSCs were further grown in fresh medium. When $80-90 \%$ confluence was reached, adherent cells were trypsinized and expanded at a dilution of 1:3. All cells used in the present study were of passages 3 to 4 .

Cell morphology and characterization of BM-MSCs expanded in vitro. The BM-MSCs at passages 3 or 4 were collected and resuspended in phosphate-buffered saline containing $1 \%$ bovine serum albumin (Sigma-Aldrich) at $1 \times 10^{6} \mathrm{cells} / \mathrm{ml}$. Cell aliquots were incubated with phycoerythrin-conjugated mouse anti-rat cluster of differentiation (CD)90 at a 1:200 dilution (cat. no. 554898, BD Biosciences, San Jose, CA, USA) and CD105 at a 1:150 dilution (cat. no. 562380, BD Biosciences) and fluorescein isothiocyanate-conjugated mouse anti-rat CD34 at a 1:100 dilution (cat. no. 555005; BD Biosciences) and CD29 at a $1: 200$ dilution (cat. no. 60942 ; BD Biosciences) at $37^{\circ} \mathrm{C}$ for $1 \mathrm{~h}$. Labeled cells were analyzed by flow cytometry and with FACSDiva Pro software version 3.0 (BD Biosciences).

Cell treatments. BM-MSCs were plated on culture dish overnight with complete medium in a humidified atmosphere with $20 \% \mathrm{O}_{2}$. Subsequently, the cells were transferred to be cultured under $2 \% \mathrm{O}_{2}$ in complete medium with or without $25 \mathrm{mM}$ LY294002 (Sigma-Aldrich), which is a commonly used PI3K/AKT signaling pathway inhibitor $(19,20)$. The cells cultured in complete medium at $20 \% \mathrm{O}_{2}$ served as the control group. In total, there were three study groups, including the normoxia (control), hypoxia group and hypoxia+LY294002 groups.

Determination of AKT activation. Western blot analysis was performed in order to detect the expression levels of AKT and phosphorylated AKT (p-AKT), since the phosphorylation of AKT represents the activation of the PI3K/AKT signaling pathway $(19,21)$. Briefly, $3 \times 10^{5}$ cells were treated as described above for 7 days, and $3 \times 10^{6}$ cells were harvested and lysed with M-PER lysis buffer (Pierce Biotechnology, Inc., Rockford, IL, USA) followed by centrifugation at 12,000 x $g$ at $4^{\circ} \mathrm{C}$ for $10 \mathrm{~min}$. The supernatants were then collected, and protein concentration was determined using a BCA assay kit (Invitrogen; Thermo Fisher Scientific, Inc). In all cell groups, $20 \mathrm{mg}$ cellular protein was resolved to 10\% SDS-PAGE and transferred onto polyvinylidene difluoride membranes. The membranes were washed once with Tris-buffered saline with $0.1 \%$ Tween 20 (TBST) then blocked for $1 \mathrm{~h}$ at room temperature with 5\% skim milk in Tris-buffered saline containing $0.1 \%$ Tween 20 . Then, membranes were probed with primary antibodies against p-AKT (1:1,000 dilution; cat. no. 4060; Cell Signaling Technology, Inc., Danvers, MA, USA), AKT (1:1,500 dilution; cat. no. 4691; Cell Signaling Technology, Inc.) and $\beta$-actin (1:2,000 dilution; cat. no. 3700; Cell Signaling Technology, Inc.) overnight at $4^{\circ} \mathrm{C}$. The membranes were then washed with TBST three times and incubated horseradish peroxidase-conjugated mouse anti-rabbit IgG (1:3,000 dilution; cat. no. 5127; Cell Signaling Technology, Inc.) for $1 \mathrm{~h}$ at room temperature. The samples were then developed using chemiluminescence substrates (EMD Millipore, Billerica, MA, USA). Images of the membranes were captured using a Bio-Rad ChemiDoc XRS system (Bio-Rad Laboratories, Inc., Hercules, CA, USA), and quantified and analyzed using the Quantity One software (version 16.0; Bio-Rad Laboratories, Inc.).

Cell proliferation assay. Cell proliferation was assessed by cell counting kit-8 (CCK-8) assay (Sigma-Aldrich) according to the manufacturer's instructions. Briefly, BM-MSCs were seeded in a 96-well plate at a density of 3,000 cells/well and treated under different conditions, as described earlier. Subsequently, the cells were incubated with CCK-8 solution for $2 \mathrm{~h}$ at $37^{\circ} \mathrm{C}$. Absorbance of each well was measured at $450 \mathrm{~nm}$. The results were presented as the ration $\mathrm{OD}_{450}$ of treated cells / $\mathrm{OD}_{450}$ of control cells. Three independent experiments were performed.

Immunofluorescence staining. In order to investigate the expression of CD31 on the cell surface in the various study groups, the treated cells were grown on glass coverslips and fixed with $4 \%$ paraformaldehyde. The cells $\left(1 \times 10^{4}\right)$ were then blocked with $10 \%$ bovine serum albumin at $37^{\circ} \mathrm{C}$ for $1 \mathrm{~h}$ and incubated with rabbit anti-rat CD31 antibody (1:100 dilution; cat. no. ab32457; Abcam, Cambridge, UK) at $4^{\circ} \mathrm{C}$ overnight. Subsequent to washing, the cells were incubated with the Alexa Fluor 555-conjugated goat anti-rabbit IgG (1:100 dilution; cat. no. sc-3739; Santa Cruz Biotechnology, Inc., Dallas, TX, USA) for $1 \mathrm{~h}$ at $37^{\circ} \mathrm{C}$. The nuclei of cells were then counterstained with DAPI (Abcam). Fluorescence images of the cells were acquired using a fluorescence microscope. The number of CD31-positive cells in 10 random fields of view in the three groups was counted in order to perform statistical analysis.

Gene expression determination. Quantitative polymerase chain reaction (qPCR) was perform to detect the expression of specific genes of endothelial cells, including fms related tyrosine kinase 1 (Flt-1), fetal liver kinase 1 (Flk-1), von Willebrand factor (vWF) and vascular endothelial (VE)-cadherin. In addition, qPCR was used to measure the gene expression of VEGF, which is the most important angiogenesis-associated cytokine (22). Following appropriate treatment for 7 days, $1 \times 10^{6}$ cells were collected from each group, and total RNA was prepared from the cells using TRIzol reagent (Invitrogen; 
Table I. Primer sequences and product size.

\begin{tabular}{|c|c|c|}
\hline Gene & Primer sequence $\left(5^{\prime} \rightarrow 3^{\prime}\right)$ & Product size (bp) \\
\hline Flk-1 & $\begin{array}{l}\text { Sense: 5'-CCCGCACGAATGATATCCCA-3' } \\
\text { Anti-sense: 5'-TCCTGCAGTGCATAACCTGG-3' }\end{array}$ & 136 \\
\hline Flt-1 & $\begin{array}{l}\text { Sense: 5'-ATCCCTCAGCCTACCATCAA-3' } \\
\text { Anti-sense: 5'-AAAGCCGTTTGGCACATCT-3' }\end{array}$ & 303 \\
\hline vWF & $\begin{array}{l}\text { Sense: 5'-GATGACCCTGATGCTGTCTG-3' } \\
\text { Antisense: 5'-GTCTCCCTTGTTGCCATTGT-3' }\end{array}$ & 153 \\
\hline VE-cadherin & $\begin{array}{l}\text { Sense: 5'-CGCTTCTACCACTTCCACCT-3' } \\
\text { Anti-sense: 5'-GCGTTGTCATTCTCATCCAA-3' }\end{array}$ & 305 \\
\hline VEGF & $\begin{array}{l}\text { Sense: 5'-CAGCGACAAGGCAGACTATT-3' } \\
\text { Antisense: 5'-GTTGGCACGATTTAAGAGGG-3' }\end{array}$ & 151 \\
\hline GAPDH & $\begin{array}{l}\text { Sense: 5'-CTCATGGCCTACATGGCCTC-3' } \\
\text { Antisense: 5'-CTCATGGCCTACATGGCCTC-3 }\end{array}$ & 70 \\
\hline
\end{tabular}

Flt-1, fms-related tyrosine kinase 1; Flk-1, fetal liver kinase 1; vWF, von Willebrand factor; VE, vascular endothelial; VEGF, vascular endothelial growth factor.

Thermo Fisher Scientific, Inc.) according to the manufacturer's instructions. Next, the total RNA was reverse-transcribed into complementary DNA using GeneAmp RNA PCR Core kit (Applied Biosystems; Thermo Fisher Scientific, Inc., Foster City, CA, USA). Quantitative gene expression was subsequently determined with the Mastercycler Realplex S instrument (Eppendorf, Hamburg, Germany) with the SYBR Green Realtime PCR Master Mix (Toyobo, Osaka, Japan). The reaction was performed in a $20 \mu 1$ system, including the following: $10 \mu \mathrm{l}$ SYBR Premix Ex Taq II, $1 \mu \mathrm{l}$ cDNA, $2 \mu \mathrm{l}$ primers, and $7 \mu \mathrm{l}$ ultrapure water. All primers were designed using primer 5.0 and synthesized by Shenggong Biotech Co., Ltd. (Shanghai, China). The gene primer sequences are shown in Table I. PCR amplification was performed as follows: One cycle of denaturation at $94^{\circ} \mathrm{C}$ for $4 \mathrm{~min}$, followed by 40 cycles of denaturation at $94^{\circ} \mathrm{C}$ for $30 \mathrm{sec}$, annealing at the appropriate temperature for $30 \mathrm{sec}$, and extension/fluorescence acquisition at $72^{\circ} \mathrm{C}$ for $30 \mathrm{sec}$. Absolute gene transcription was normalized to GAPDH. The relative expression level of the target mRNA was plotted as a fold change compared with the control using the $2-\Delta \Delta \mathrm{Cq}$ method (23).

Statistical analysis. All values were expressed as the mean \pm standard deviation. Analysis of variance with Dunnett's test was used to determine statistically significant differences in multiple comparisons, which were indicated by values of $\mathrm{P}<0.05$. All statistical analyses were performed using SPSS software, version 16.0 (SPSS, Inc., Chicago, IL, USA).

\section{Results}

Characterization of BM-MSCs. As shown in Fig. 1A, rat BM-MSCs at passage 3 or 4 were demonstrated to have an elongated fibroblast-like morphology. Fluorescence-activated cell sorting analysis of BM-MSCs revealed that the majority of cells were negative for the lineage cell marker CD34, whereas they strongly expressed typical surface antigens of stem cells, including CD90, CD105 and CD29 (Fig. 1B).
AKT activation detected by western blot analysis. Western blot analysis was performed to analyze AKT and p-AKT expression, and the result was displayed as the fold of p-AKT to total AKT. $\beta$-actin was used as an internal control. In the hypoxia group, higher expression of $\mathrm{p}$-AKT was observed when compared with the control group $(\mathrm{P}<0.001)$, suggesting that the PI3K/AKT signaling pathway was activated. However, upon the addition of LY294002, the expression of p-AKT was evidently decreased as compared with the hypoxia group $(\mathrm{P}=0.04)$ (Fig. 2A and $\mathrm{B})$. These findings indicated that hypoxia was able to effectively activate the PI3K/AKT pathway, and that LY294002 was a potent inhibitor of the PI3K/AKT pathway, which is consistent with the results of previous studies $(24,25)$.

Cell proliferation after different treatments. As shown in Fig. 2C, the proliferation of cultured BM-MSCs in the hypoxia group at days 2 and 3 was much higher compared with that in the normoxia group ( $\mathrm{P}=0.030$ and $\mathrm{P}=0.017$, respectively). In the hypoxia group treated with LY294002, the cell proliferation at day 3 remained significantly higher compared with that in cells cultured in normoxia $(\mathrm{P}=0.026)$. These findings demonstrated that hypoxia was able to significantly enhance the proliferation of cultured BM-MSCs, and this effect was partly inhibited by PI3K/AKT pathway inhibitor (Fig. 2C).

Endothelial cell differentiation of rat BM-MSCs. After culturing under hypoxia for 7 days, immunofluorescence staining results showed that approximately 32.25 $\pm 3.5 \%$ BM-MSCs expressed CD31, a known marker of endothelial cells, which was significantly higher compared with the percentage in the normoxia group (1.4 $\pm 0.2 \%$; $<<0.001$; Fig. 3). In the hypoxia+LY294002 group, the percentage of differentiated cells decreased to $8.47 \pm 1.2 \%$, which was significantly different compared with both the normoxia $(\mathrm{P}=0.035)$ and hypoxia groups $(\mathrm{P}=0.024)$ (Fig. 3).

Hypoxia upregulates the expression of endothelial cell-specific genes. qPCR analysis was performed to 
A

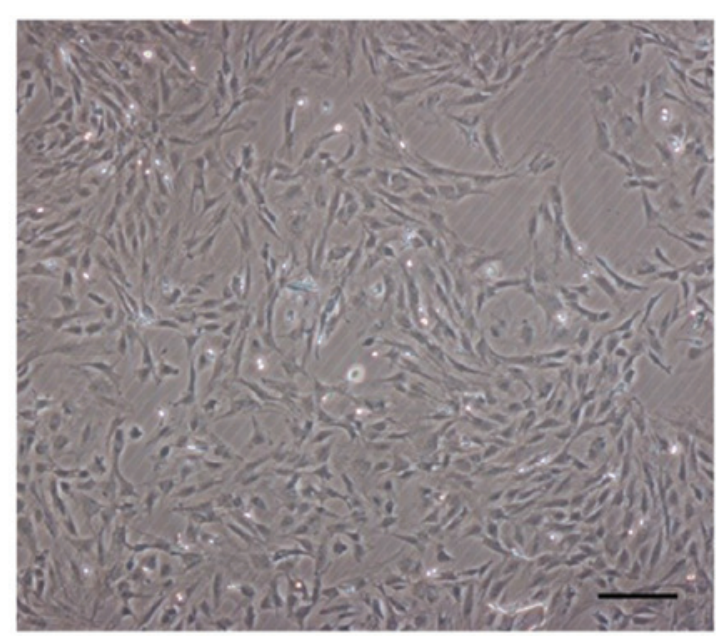

B
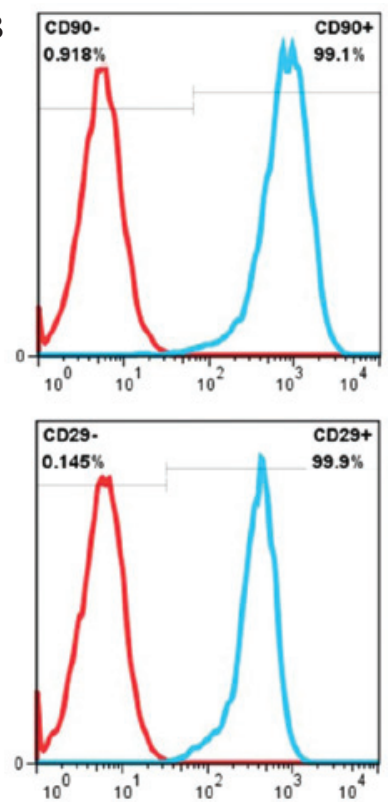
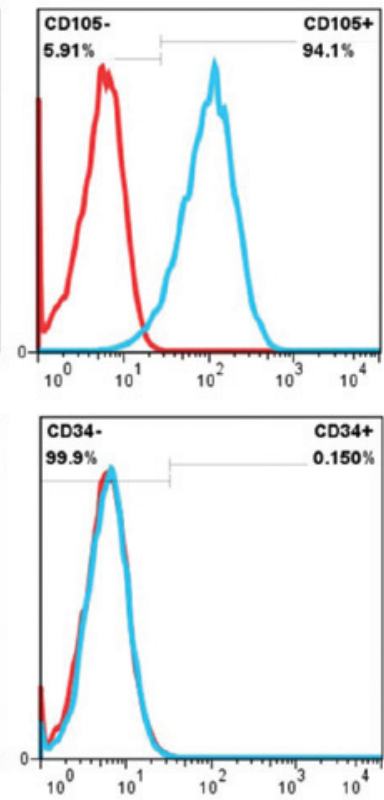

Figure 1. Morphology of rat BM-MSCs and flow cytometric analysis of BM-MSCs expanded to passage 3 under normoxic conditions. (A) BM-MSCs exhibit an elongated fibroblast-like morphology. Scale bar, $40 \mu \mathrm{m}$. (B) The majority of BM-MSCs express CD90, CD105 and CD29, but are negative for CD34. BM-MSC, bone marrow-derived mesenchymal stem cell.

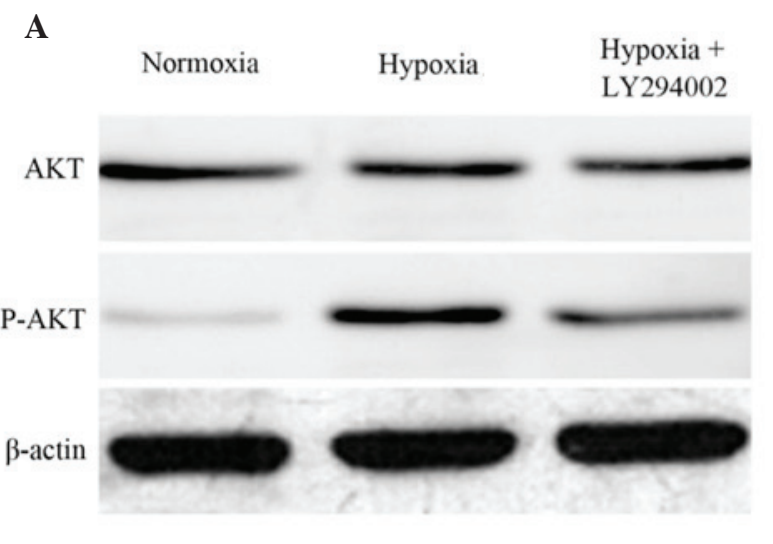

B

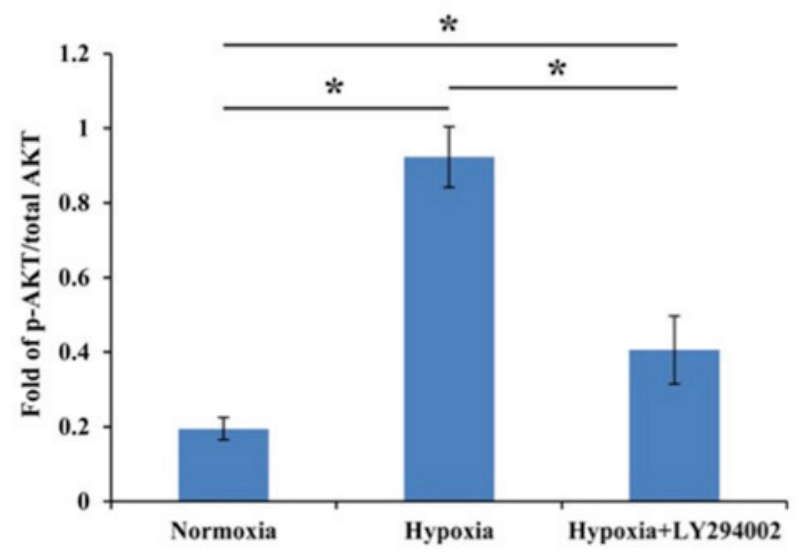

C

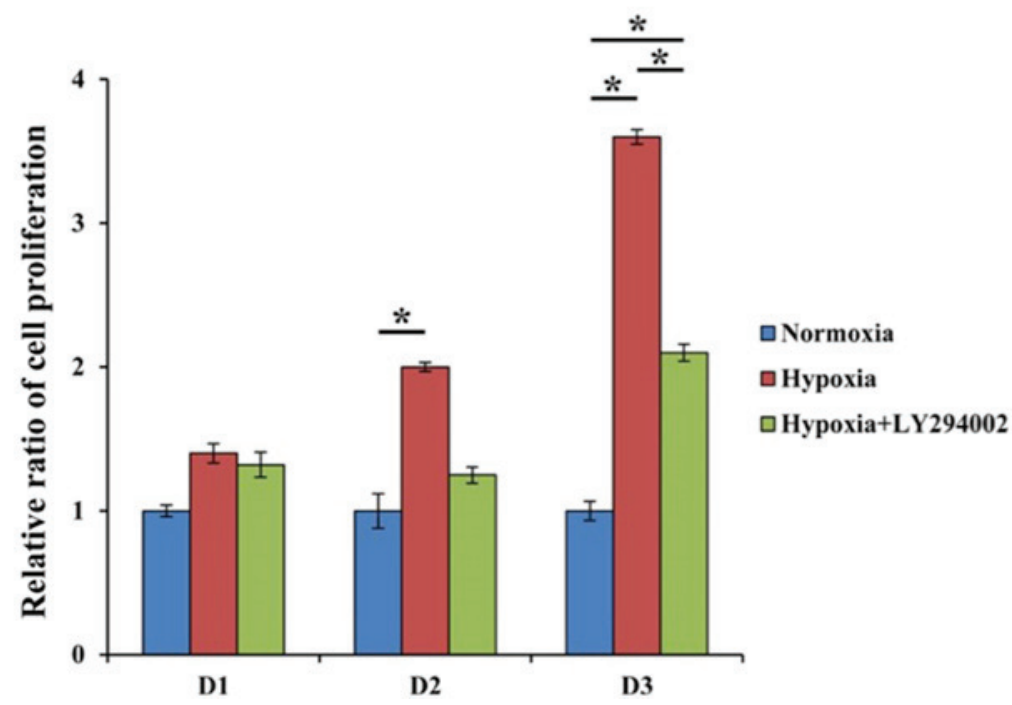

Figure 2. Western blot analysis of the expression of AKT and p-AKT and cell proliferation following various treatments. (A) PI3K/AKT signaling was activated during hypoxia, as evidenced by the marked expression of p-AKT and a higher ratio of p-AKT/total AKT. Treatment with LY294002 decreased AKT expression and the corresponding ration of p-AKT/total AKT. (B) Hypoxia enhanced cell proliferation compared with normoxia following treatment for 2 and 3 days. (C) Cell proliferation decreased following treatment with LY294002 at day 3, ${ }^{*}<0.05$. p-AKT, phosphorylated protein kinase B; PI3K, phosphatidylinositide 3-kinase. 
A
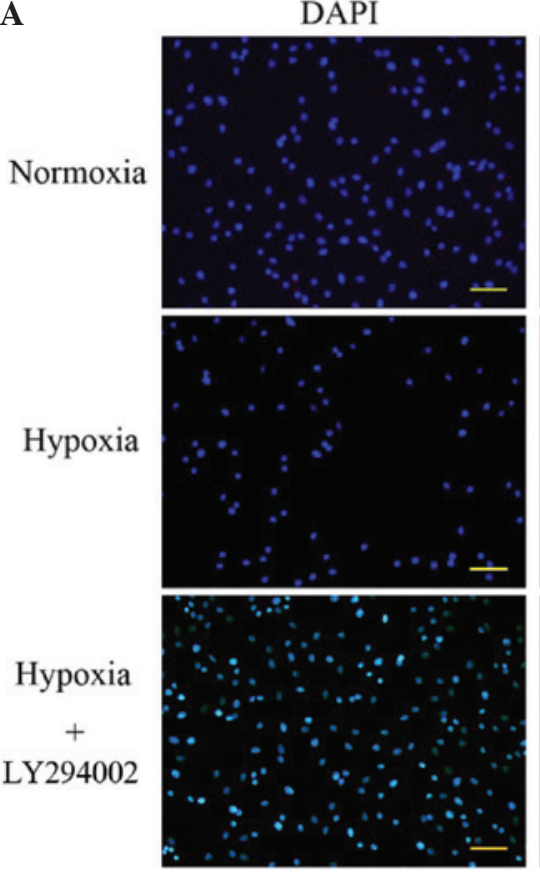

Anti-CD31
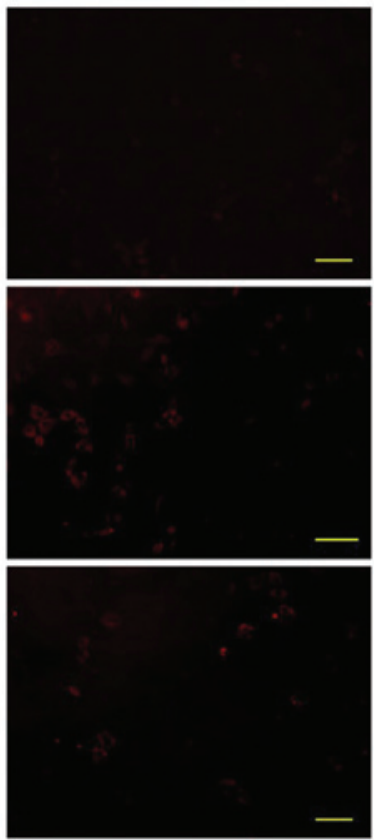

B
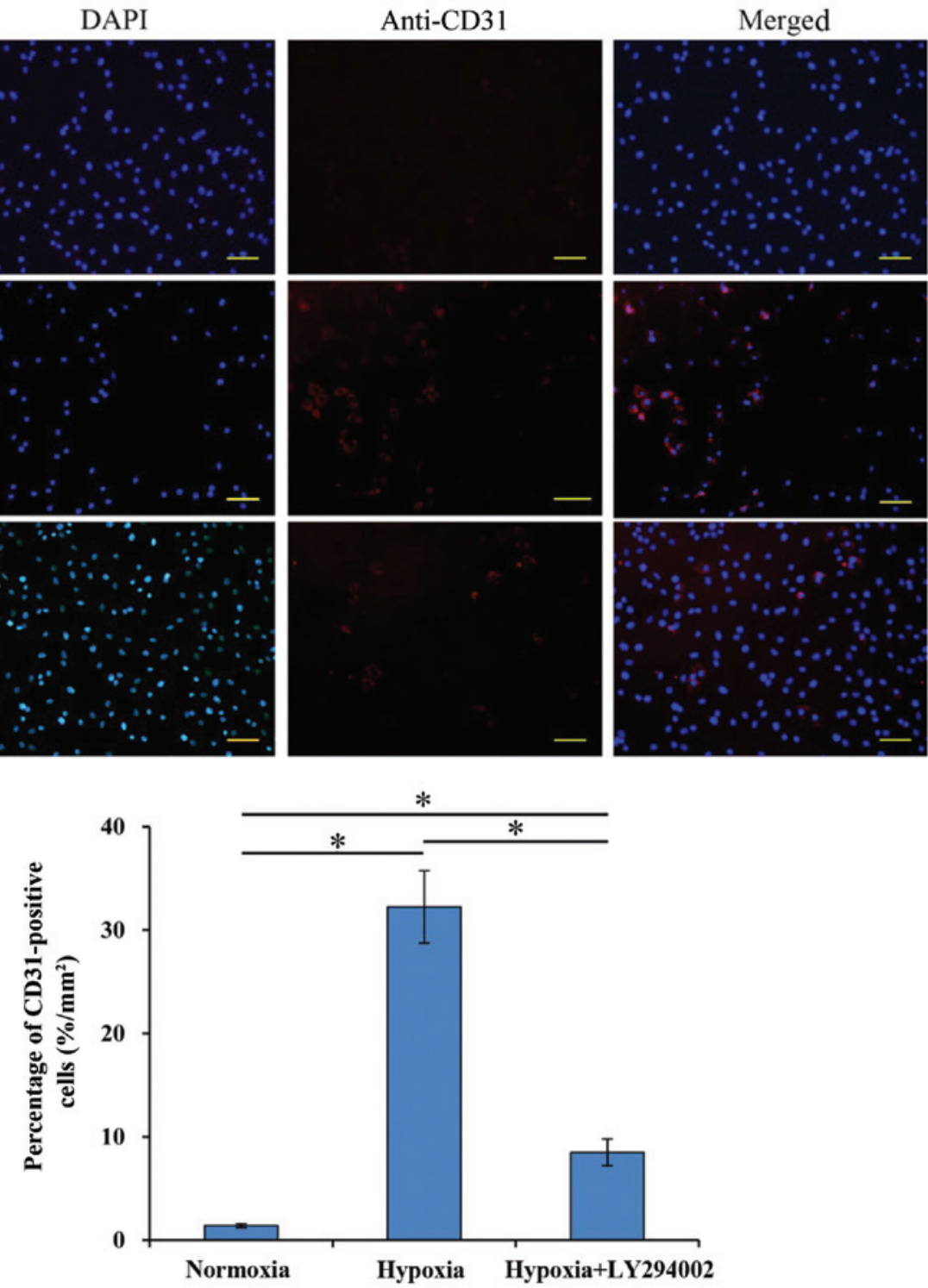

Figure 3. The expression of CD31 after culture for 7 days. (A) Representative images of anti-CD31 immunofluorescence staining. The cellular localization of CD31 was the cytomembrane. After merging DAPI and anti-CD31 stainings, the positive cells represented the endothelial cells. Scale bar, $40 \mu \mathrm{m}$. (B) The density of CD31-positive cells in the hypoxia group was significantly increased compared with the other two groups. LY294002 inhibited the differentiation of BM-MSCs into endothelial cells. " $\mathrm{P}<0.05$. BM-MSC, bone marrow-derived mesenchymal stem cell; DAPI, 4',6-diamidino-2-phenylindole.

investigate the relative mRNA expression of endothelial cell-specific genes in the three study groups. The results demonstrated that hypoxia significantly upregulated the mRNA expression levels of Flk-1 (4.98-fold), Flt-1 (3.29-fold), vWF (4.76-fold) and VE-cadherin (5.08-fold) when compared with those in the normoxia group (Fig. 4A). Following the addition of LY294002 under hypoxia, the mRNA expression levels decreased for Flk-1 (2.33-fold), Flt-1 (2.34-fold), vWF (1.52-fold) and VE-cadherin (3.17-fold) when compared with those in the normoxia group, with a significant decrease observed for all genes except vWF. Furthermore, the mRNA expression of these genes was significantly reduced in the hypoxia+LY294002 group when compared with that in the hypoxia group, with the exception of Flt-1 that did not present a significant decrease (Fig. 4A).

VEGF expression induced by hypoxia. In hypoxic condition, treated cells showed a significantly higher VEGF gene expression $(12.9 \pm 0.16$-fold) compared with that of cells cultured under normoxia $(\mathrm{P}<0.001)$. Furthermore, after addition of LY294002, the expression of VEGF gene in hypoxia was $4.85 \pm 0.43$ times greater than that of the normoxia group, and the difference was statistically significant $(\mathrm{P}=0.040)$. There was also a statistical significant difference between the hypoxia groups with and without LY294002 ( $\mathrm{P}=0.003$; Fig. 4B).

\section{Discussion}

Stem cell transplantation represents an attractive technique for use in tissue engineering and reparative medicine. For the improvement of the therapeutic potential of BM-MSCs, a more comprehensive understanding of the in vitro culture parameters that can maintain their stem-cell phenotype and multipotent capabilities during expansion is required (7). Oxygen has been demonstrated to be a potent signaling molecule due to its 

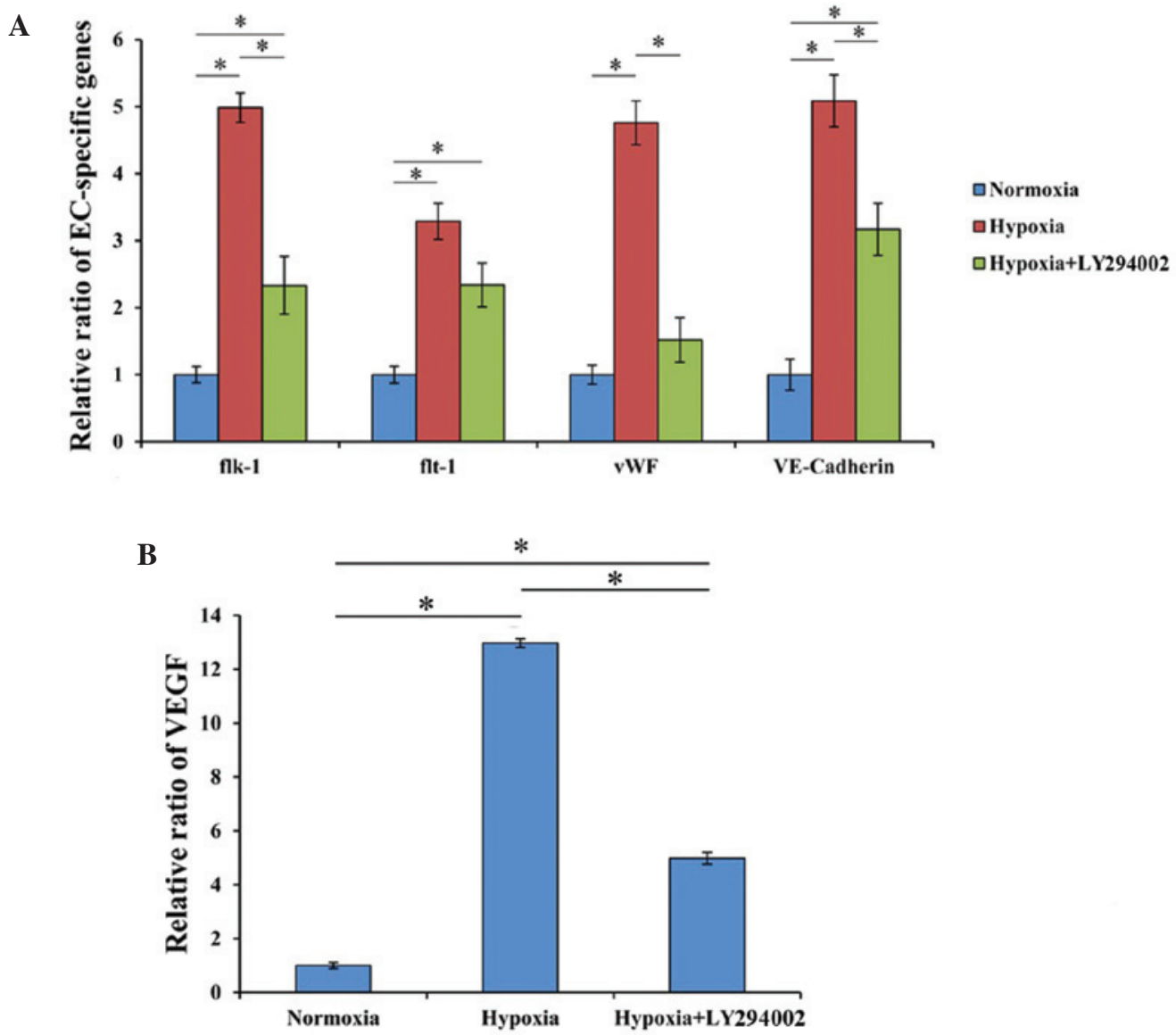

Figure 4. Expression of endothelial cell-specific genes and VEGF. (A) Hypoxia significantly increased the expression of endothelial cell-specific genes in BM-MSCs, including Flk-1, Flt-1, vWF and VE-cadherin, as compared with the cells cultured under normoxic conditions. Following inhibition with LY294002, the hypoxia-induced expression of the endothelial cell-specific genes was significantly decreased. ${ }^{*} \mathrm{P}<0.05$. (B) The highest expression levels of VEGF were observed in the hypoxia group, and LY294002 significantly decreased VEGF expression levels. " $\mathrm{P}<0.05$. BM-MSC, bone marrow-derived mesenchymal stem cell; EC, endothelial cell; Flt-1, fms-related tyrosine kinase 1; Flk-1, fetal liver kinase 1; vWF, von Willebrand factor; VE, vascular endothelial; VEGF, vascular endothelial growth factor.

ability to affect the fundamental characteristics of various types of progenitor cells, including their proliferation, differentiation and gene expression $(6,26)$.

In the present study, BM-MSCs were cultured under $2 \% \mathrm{O}_{2}$, which is considered as mild to moderate level of hypoxia, for the investigation of cell biology and possible underlying mechanisms. The results showed that the PI3K/AKT signaling pathway was activated by hypoxia, as indicated by the high expression of p-AKT, which is the activated state of AKT. In addition, in order to examine the effect of PI3K/AKT pathway on the influence of hypoxia on BM-MSCs, a PI3K/AKT inhibitor was used to prevent the signaling of this pathway.

Low oxygen is a potent proliferation regulator of numerous cell types $(6,25)$. In the present study, the hypoxic culture conditions evidently induced BM-MSC proliferation; however, following treatment with LY294002, the proliferation decreased markedly. This result indicated that the PI3K/AKT pathway served an important role in the process of cell proliferation induced by hypoxia. Numerous studies have focused on the role of PI3K/AKT in cell proliferation. For instance, Watanabe et al (27) demonstrated that impaired PI3K/AKT activation directly contributes to the effect of aging on pancreatic acinar cell proliferation. In addition, Mangi et al (28) genetically modified MSCs with AKT using retroviruses and found that the engineered AKT-MSCs were more resistant to hypoxic injury. The role of PI3K/AKT in promoting cell proliferation may rely on phosphorylating the pro-apoptotic protein $\operatorname{Bad}(29,30)$ or caspase-9 (31), which may account for the antiapoptotic effect of AKT, thereby inhibiting its pro-apoptotic function.

Hypoxia is also a potent differentiation inducer towards endothelial cell differentiation. In a previous study, BM-MSCs were treated with VEGF under hypoxic conditions, and a greater proportion of BM-MSCs differentiated into endothelial cells when compared with those cultured under standard conditions (8). Xiao et al (22) demonstrated that PI3K/AKT signaling pathway served an important role in rat cardiac stem cell differentiation into endothelial cells, while Wortmannin (a PI3K/AKT signaling pathway inhibitor) was able to decrease this differentiation. Other than its role in promoting differentiation towards endothelial cells, the PI3K/AKT pathway has been shown to participate in improving neovascularization of human umbilical vein endothelial cells, and LY294002 has been demonstrated to abolish this positive effect (32). Therefore, the present study examined the role of PI3K/AKT pathway in BM-MSC differentiation. The results revealed that the PI3K/AKT signaling pathway inhibitor LY294002 decreased the differentiation of BM-MSCs towards endothelial cells, which was induced by hypoxia. 
A previous in vitro study indicated that conditional medium without stem cells attenuated myocardial reperfusion injury, and the cardioprotection effect was mediated by the activation of PI3K/AKT pathway through paracrine factors (33). These observations suggested the important role of PI3K/AKT pathway in the paracrine function of BM-MSCs. In ischemia therapy, angiogenesis is crucial. Amongst all the molecules participating in angiogenesis, VEGF is particularly relevant since it modulates the function of vascular and non-vascular cells (34) and promotes every step of angiogenesis, in both physiological and pathological conditions (35). Therefore, in the current study, VEGF expression was detected to represent the role of PI3K/AKT pathway in BM-MSC paracrine function caused by hypoxia. Following treatment with the PI3K/AKT inhibitor under hypoxia, VEGF expression in the BM-MSCs decreased conspicuously. This result was consistent with the findings of a previous study, which demonstrated that the migration ability and cytokine paracrine function of BM-MSCs were attenuated by a PI3K/AKT pathway inhibitor, leading to a decreased mobilization, homing of BM-MSCs and angiogenesis (36).

In conclusion, stem cell transplantation is widely applied in ischemia treatment; however, the effect of low oxygen on the engrafted cells remains unclear. Improved understanding of the effect of hypoxia is essential in order to improve the use of stem cell-based therapy. The results in the present study indicated that hypoxia promoted the proliferation, differentiation into endothelial cells and VEGF expression of BM-MSCs, and thus the PI3K/AKT signaling pathway may serve an important role in this effect. The current study provides an insight into a potentially intriguing pathway, which may assist further studies in stem cell-based applications in ischemia therapy.

\section{Acknowledgements}

The current study was supported by the National Natural Science Foundation of China (grant no. 8127129).

\section{References}

1. Chen J, Li Y, Wang L, Zhang Z, Lu D, Lu M and Chopp M: Therapeutic benefit of intravenous administration of bone marrow stromal cells after cerebral ischemia in rats. Stroke 32: 1005-1011, 2001.

2. Tse HF, Siu CW, Zhu SG, Songyan L, Zhang QY, Lai WH, Kwong YL, Nicholls J and Lau CP: Paracrine effects of direct intramyocardial implantation of bone marrow derived cells to enhance neovascularization in chronic ischaemic myocardium. Eur J Heart Fail 9: 747-753, 2007.

3. Uysal CA, Ogawa R, Lu F, Hyakusoku H and Mizuno H: Effect of mesenchymal stem cells on skin graft to flap prefabrication: An experimental study. Ann Plast Surg 65: 237-244, 2010.

4. Cao F, Lin S, Xie X, Ray P, Patel M, Zhang X, Drukker M, Dylla SJ, Connolly AJ, Chen X, et al: In vivo visualization of embryonic stem cell survival, proliferation and migration after cardiac delivery. Circulation 113: 1005-1014, 2006.

5. Horwitz EM, Prockop DJ, Fitzpatrick LA, Koo WW, Gordon PL, Neel M, Sussman M, Orchard P, Marx JC, Pyeritz RE and Brenner MK: Transplantability and therapeutic effects of bone marrow-derived mesenchymal cells in children with osteogenesis imperfecta. Nat Med 5: 309-313, 1999.

6. Zhu LL, Wu LY, Yew DT and Fan M: Effects of hypoxia on the proliferation and differentiation of NSCs. Mol Neurobiol 31: 231-242, 2005.
7. Grayson WL, Zhao F, Bunnell B and Ma T: Hypoxia enhances proliferation and tissue formation of human mesenchymal stem cells. Biochem Biophys Res Commun 358: 948-953, 2007.

8. Ren H, Cao Y, Zhao Q, Li J, Zhou C, Liao L, Jia M, Zhao Q, Cai H, Han ZC, et al: Proliferation and differentiation of bone marrow stromal cells under hypoxic conditions. Biochem Biophys Res Commun 347: 12-21, 2006.

9. Chen L, Tredget EE, Wu PY and Wu Y: Paracrine factors of mesenchymal stem cells recruit macrophages and endothelial lineage cells and enhance wound healing. PloS One 3: e1886, 2008.

10. Han SK, Chun KW, Gye MS and Kim WK: The effect of human bone marrow stromal cells and dermal fibroblasts on angiogenesis. Plast Reconstr Surg 117: 829-835, 2006.

11. Mohyeldin A, Garzón-Muvdi T and Quiñones-Hinojosa A: Oxygen in stem cell biology: A critical component of the stem cell niche. Cell Stem Cell 7: 150-161, 2010.

12. Yew TL, Chang MC, Hsu YT, He FY, Weng WH, Tsai CC, Chiu FY and Hung SC: Efficient expansion of mesenchymal stem cells from mouse bone marrow under hypoxic conditions. J Tissue Eng Regen Med 7: 984-993, 2013.

13. Hung SP, Ho JH, Shih YR, Lo T and Lee OK: Hypoxia promotes proliferation and osteogenic differentiation potentials of human mesenchymal stem cells. J Orthop Res 30: 260-266, 2012.

14. Cicione C, Muiños-López E, Hermida-Gómez T, Fuentes-Boquete I, Díaz-Prado S and Blanco FJ: Effects of severe hypoxia on bone marrow mesenchymal stem cells differentiation potential. Stem Cells Int 2013: 232896, 2013.

15. Chen L, Xu Y, Zhao J, Zhang Z, Yang R, Xie J, Liu X and Qi S: Conditioned medium from hypoxic bone marrow-derived mesenchymal stem cells enhances wound healing in mice. PLoS One 9: e96161, 2014

16. Jung F, Haendeler J, Goebel C, Zeiher AM and Dimmeler S: Growth factor-induced phosphoinositide 3-OH kinase/Akt phosphorylation in smooth muscle cells: Induction of cell proliferation and inhibition of cell death. Cardiovasc Res 48: 148-157, 2000.

17. Ma J, Sawai H, Ochi N, Matsuo Y, Xu D, Yasuda A, Takahashi $\mathrm{H}$, Wakasugi $\mathrm{T}$ and Takeyama $\mathrm{H}$ : PTEN regulates angiogenesis through PI3K/Akt/VEGF signaling pathway in human pancreatic cancer cells. Mol Cell Biochem 331: 161-171, 2009.

18. Zhang Z, Zhao C, Liu B, Liang D, Qin X, Li X, Zhang R, Li C, Wang H, Sun D and Cao F: Inositol pyrophosphates mediate the effects of aging on bone marrow mesenchymal stem cells by inhibiting Akt signaling. Stem Cell Res Ther 5: 33, 2014.

19. Zhou N, Lu F, Liu C, Xu K, Huang J, Yu D and Bi L: IL-8 induces the epithelial-mesenchymal transition of renal cell carcinoma cells through the activation of AKT signaling. Oncol Lett 12: 1915-1920, 2016.

20. Huang P, Li Y, Lv Z, Wang J, Zhang Q, Yao X, Corrigan CJ, Huang K, Wang W and Ying S: Comprehensive attenuation of IL-25-induced airway hyperresponsiveness, inflammation and remodelling by the PI3K inhibitor LY294002. Respirology: 24 Aug, 2016 (Epub ahead of print).

21. Tong X and Pelling JC: Targeting the PI3K/Akt/mTOR axis by apigenin for cancer prevention. Anticancer Agents Med Chem 13: 971-978, 2013.

22. Xiao N, Qi XY, Tang LN, Tan LL, Chen YQ and Zhao HM: VEGF promotes cardiac stem cells differentiation into vascular endothelial cells via the PI3K/Akt signaling pathway. Artif Cells Nanomed Biotechnol 42: 400-405, 2014.

23. Livak KJ and Schmittgen TD: Analysis of relative gene expression data using real-time quantitative PCR and the 2- $\Delta \Delta \mathrm{Ct}$ method. Methods 25: 402-408, 2001.

24. Chen L, Tao Y and Jiang Y: Apelin activates the expression of inflammatory cytokines in microglial BV2 cells via PI-3K/Akt and MEK/Erk pathways. Sci China Life Sci 58: 531-540, 2015.

25. Caraci F, Battaglia G, Busceti C, Biagioni F, Mastroiacovo F, Bosco P, Drago F, Nicoletti F, Sortino MA and Copani A: TGF-beta 1 protects against Abeta-neurotoxicity via the phosphatidylinositol-3-kinase pathway. Neurobiol Dis 30: 234-242, 2008.

26. Csete M: Oxygen in the cultivation of stem cells. Ann N Y Acad Sci 1049: 1-8, 2005.

27. Watanabe H, Saito H, Ueda J and Evers BM: Regulation of pancreatic duct cell differentiation by phosphatidylinositol-3 kinase. Biochem Biophys Res Commun 370: 33-37, 2008. 
28. Mangi AA, Noiseux N, Kong D, He H, Rezvani M, Ingwall JS and Dzau VJ: Mesenchymal stem cells modified with Akt prevent remodeling and restore performance of infarcted hearts. Nat Med 9: 1195-1201, 2003.

29. Datta SR, Dudek H, Tao X, Masters S, Fu H, Gotoh Y and Greenberg ME: Akt phosphorylation of BAD couples survival signals to the cell-intrinsic death machinery. Cell 91: 231-241, 1997.

30. Bai Hz, Pollman MJ, Inishi Y and Gibbons GH: Regulation of vascular smooth muscle cell apoptosis. Modulation of bad by a phosphatidylinositol 3-kinase-dependent pathway. Circ Res 85: 229-237, 1999.

31. Cardone MH, Roy N, Stennicke HR, Salvesen GS, Franke TF, Stanbridge E, Frisch S and Reed JC: Regulation of cell death protease caspase-9 by phosphorylation. Science 282: 1318-1321, 1998.

32. Xiao X, Wang W, Liu D, Zhang H, Gao P, Geng L, Yuan Y, $\mathrm{Lu} \mathrm{J}$ and Wang $\mathrm{Z}$ : The promotion of angiogenesis induced by three-dimensional porous beta-tricalcium phosphate scaffold with different interconnection sizes via activation of PI3K/Akt pathways. Sci Rep 5: 9409, 2015
33. Angoulvant D, Ivanes F, Ferrera R, Matthews PG, Nataf S and Ovize M: Mesenchymal stem cell conditioned media attenuates in vitro and ex vivo myocardial reperfusion injury. J Heart Lung Transplant 30: 95-102, 2011.

34. Fox SB, Gatter KC and Harris AL: Tumour angiogenesis. J Pathol 179: 232-237, 1996.

35. Hicklin DJ and Ellis LM: Role of the vascular endothelial growth factor pathway in tumor growth and angiogenesis. J Clin Oncol 23: 1011-1027, 2005.

36. He H, Zhao ZH, Han FS, Wang XF and Zeng YJ: Activation of protein kinase $\mathrm{C} \varepsilon$ enhanced movement ability and paracrine function of rat bone marrow mesenchymal stem cells partly at least independent of SDF-1/CXCR4 axis and PI3K/AKT pathway. Int J Clin Exp Med 8: 188-202, 2015. 